\title{
Acute coronary syndromes and atherosclerotic plaque burden distribution in coronary arteries among patients with valvular heart disease (BIA-WAD registry)
}

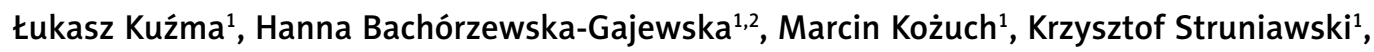 \\ Szymon Pogorzelski ${ }^{1}$, Tomasz Hirnle ${ }^{3}$, Sławomir Dobrzycki ${ }^{1}$
}

${ }^{1}$ Department of Invasive Cardiology, Medical University of Bialystok, Bialystok, Poland

${ }^{2}$ Department of Clinical Medicine, Medical University of Bialystok, Bialystok, Poland

${ }^{3}$ Department of Cardiac Surgery, Medical University of Bialystok, Bialystok, Poland

Adv Interv Cardiol 2019; 15, 4 (58): 422-430

DOI: https://doi.org/10.5114/aic.2019.90216

\begin{abstract}
A bstract
Introduction: Valvular heart diseases (VHD) are a significant problem in the Polish population. Coexistence of coronary artery disease (CAD) in patients with VHD increases the risk of death and affects the further therapeutic strategy.

Aim: Analysis of atherosclerotic plaque burden distribution in coronary arteries and long-term prognosis among patients with VHD.

Material and methods: Inclusion criteria were met by 1025 patients with moderate and severe VHD. Mean observation time was $2528 \pm 1454$ days.

Results: Severe aortic valve stenosis (AVS) occurred in $28.2 \%$, severe mitral valve insufficiency (MVI) in $20 \%$. CAD with severe angiographic stenoses was noted in $42.3 \%(n=434)$. Among patients with severe MVI, CAD was noted in $47.1 \%$ of cases, and prior acute coronary syndromes (ACS) in $27.1 \%$ of patients $(n=58)$. In severe AVS patients, significant angiographic atherosclerotic changes were observed in $29.6 \%(n=86)$, and prior ACS in $7.6 \%(n=22)$ of patients. During the observation $52.7 \%$ of patients died, including $62.9 \%$ of patients with severe MVI and $51.6 \%$ of those with severe AVS. Age (OR $=1.038 ; 95 \% \mathrm{Cl}: 1.005-1.072 ; p=0.022)$ and coexisting aortic valve insufficiency $(\mathrm{AVI})(\mathrm{OR}=2.39,95 \% \mathrm{Cl}: 5.370-11.065, p=0.035)$ increased the mortality rate.

Conclusions: Severe AVS is starting to be the most prevalent VHD. CAD is one of the most significant factors deteriorating prognosis of patients with VHD. AVI and age were significant risk factors for mortality. The worst prognosis was observed in severe $M V I$, which may result from more frequent occurrence of CAD in this group. A lesser burden of CAD and ACS in the group of patients with severe AVS did not affect survival.
\end{abstract}

Key words: aortic stenosis, mitral insufficiency, coronary artery disease, myocardial infarction.

S u m m a ry

Coexistence of coronary artery disease (CAD) in patients with valvular heart diseases (VHD) increases the risk of death and affects the further therapeutic strategy. Patients with mitral valve insufficiency are most burdened with CAD and prior acute coronary syndrome. Coexistence of coronary artery disease in patients with VHD increases the risk of death and has an influence on the choice of therapeutic strategy.

\section{Introduction}

Cardiovascular diseases are responsible for $46 \%$ of deaths in the Polish population despite the constantly developing progress in medical sciences [1]. The most common cardiovascular disorders are coronary artery disease, including acute coronary syndromes, and valvular heart disease (VHD), the frequency of which has been growing continuously in recent years. The greatest increase in prevelance is observed for aortic stenosis (AVS), whereas the number of mitral stenosis cases (MVS) has dropped significantly [2, 3]. This association was reported

\section{Corresponding author:}

Łukasz Kuźma MD, PhD, Department of Invasive Cardiology, Medical University of Bialystok, 24 A Sklodowskiej-Curie St, 15 -276 Bialystok, Poland, phone: +48 8583184 96, e-mail: kuzma.lukasz@gmail.com

Received: 23.04.2019, accepted: 11.08.2019. 
in both national and global registries. The European Registry of Valvular Heart Diseases contains records of 5001 patients from 92 centers from 25 countries. The analysis includes patients in moderate and severe grading of valvular heart disease. The most frequently occurring disease is aortic stenosis (33.9\%) and mitral insufficiency (MVI) (24.8\%). In the largest Polish registry, WAD-POL, containing 1663 patients; aortic stenosis was found in $27.5 \%$, and mitral regurgitation in $38.0 \%$ of the population [4]. The reason for the prevalence of aortic valve stenosis patients stems from the degenerative etiology of the disease [5]. Demographic analyses considering dynamic aging of the Polish society show that there will be nearly 200,000 more elderly in the third decade of the $21^{\text {st }}$ century [6]. The population's longer survival rate corresponds with an increased percentage of valvular heart diseases of degenerative etiology and worse prognosis of those with coexisting diseases such as coronary artery disease (CAD) or myocardial infarction. Not only does coronary artery disease have similar risk factors as aortic stenosis, but also it is of degenerative and atherosclerotic etiology. Therefore, it is not surprising that advanced coronary artery disease often coexists with valvular heart diseases. Moreover, such patients have a history of acute coronary syndrome (ACS), which has a particular influence on the choice of therapeutic strategy.

Until the beginning of the $21^{\text {st }}$ century, conventional cardiosurgical methods such as valve replacement (VR) were a standard treatment for patients with valvular heart diseases, yet only within the last 10 years have they gradually been substituted by low-invasive techniques. The most widespread procedure is transcatheter aortic valve implantation (TAVI), while a non-surgical approach for mitral regurgitation treatment is also being introduced [7-9]. These methods are particularly indicated in high-risk patients, providing better prognosis.

Taking into consideration insufficient data of patients with coronary artery disease and valvular heart disease, this study provides information of mentioned subjects.

\section{Aim}

Analysis of atherosclerotic plaque burden distribution in coronary arteries and long-term prognosis among patients with valvular heart disease.

\section{Material and methods}

Medical records of 12954 patients hospitalized in the Department of Invasive Cardiology of the Medical University of Bialystok in 2006-2010 were analyzed. 1025 patients with moderate and severe valvular heart disease met the inclusion criteria.

Assignment of patients to particular groups was based on the ESC guidelines for the management of valvular heart disease published in 2012 [5]. Prior cardiosurgical valve replacement was the exclusion criterion.
The set of variables subjected to interpretation consisted of demographic data, medical history, coronary angiography, percutaneous and surgical treatment. Follow-up study included the analysis of medical documentation of the Cardiosurgery Department and the Invasive Cardiology Department of the Medical University of Bialystok, phone call interview and provided information on the duration and type of procedure performed. There was no follow-up concerning the aforementioned data in $26(2.5 \%)$ cases. All-cause mortality was collected from the Polish Ministry of Digital Affairs on 09.11.2018. The mean follow-up period from the onset to the procedure was $360 \pm 796$ days, and that from the cardiosurgical procedure to death was $2480 \pm 1445$ days. Complete follow-up duration was $2528 \pm 1454$ days.

The study was approved by the Local Bioethics Committee of the Medical University of Bialystok no. R-I002/20/2013.

\section{Statistical analysis}

Distribution of the variables was assessed with the Kolmogorov-Smirnov test. Student's $t$-test was applied for comparative analysis of continuous variables. Evaluation of differences between dichotomic variables was performed using the $\chi^{2}$ test. The Wald test for logistic regression was used to determine mortality risk factors. $P<0.05$ was considered statistically significant.

\section{Results}

One hundred and twenty-five patients with moderate and severe valvular heart disease were included in the study. The mean age of the study population was 67.1 \pm 10.3 years, mostly male $(56.6 \%)$ (Table I). Aortic valve stenosis was the most common defect and occurred in $28.2 \%$ of studied subjects $(n=289)$, while severe mitral regurgitation was found in 210 (20.5\%) patients. Severe aortic regurgitation and severe aortic stenosis occurred in a similar percentage and affected $8 \%$ of patients. The most prevalent severe, combined valve disease was coexisting aortic valve stenosis and mitral valve insufficiency $(n=13)$. The remaining severe multivalve disorders were found in single cases (Tables I and II).

Coronary artery disease occurred in $73.4 \%$ of the subjects $(n=752)$, significant angiographic stenoses were noted in $42.3 \%(n=434)$ of patients, including the left anterior descending artery (LAD) $24.9 \%(n=256)$, left circumflex artery (CX) $23.0 \%(n=236)$ and right coronary artery (RCA) $22.9 \%(n=235)$. Significant atherosclerotic lesions in the left main coronary artery (LM) were observed in $4.1 \%$ of patients $(n=42)$ (Figure 1$)$. In the group with severe MVI, coronary artery disease was found in $47.1 \%$ of cases, and prior acute coronary syndrome in $27.1 \%$ of patients $(n=58)$. In the group with severe AVS, significant angiographic atherosclerotic changes were observed in $29.6 \%(n=86)$ and prior ACS in $7.6 \%$ 
Table I. Valvular heart disease and coronary artery disease in the analyzed population

\begin{tabular}{|c|c|c|c|c|c|}
\hline Parameter & $\begin{array}{l}\text { All patients } \\
(N=1025)\end{array}$ & $\begin{array}{l}\text { Patients with } \\
\text { aortic stenosis } \\
\quad(N=411)\end{array}$ & $\begin{array}{l}\text { Patients with } \\
\text { aortic insufficien- } \\
\text { cy }(N=194)\end{array}$ & $\begin{array}{l}\text { Patients with } \\
\text { mitral stenosis } \\
\quad(N=74)\end{array}$ & $\begin{array}{l}\text { Patients with mi- } \\
\text { tral insufficiency } \\
\quad(N=531)\end{array}$ \\
\hline Age & $67.1(S D=10.1)$ & $68.0(S D=10.1)$ & $64.1(S D=10.4)$ & $64.7(S D=9.1)$ & $67.2(S D=10.1)$ \\
\hline Male & $56.7 \%(N=579)$ & $58.2 \%(N=239)$ & $64.6 \%(N=122)$ & $24.3 \%(N=18)$ & $56.7 \%(N=301)$ \\
\hline Moderate VHD & $60.9 \%(N=624)$ & $29.7 \%(N=122)$ & $79.9 \%(N=155)$ & $55.4 \%(N=41)$ & $60.5 \%(N=321)$ \\
\hline Severe VHD & $53.6 \%(N=549)$ & $70.3 \%(N=289)$ & $20.6 \%(N=39)$ & $44.6 \%(N=33)$ & $39.5 \%(N=210)$ \\
\hline Isolated severe VHD & $42.0 \%(N=431)$ & $49.4 \%(N=203)$ & $13.4 \%(N=26)$ & $21.6 \%(N=16)$ & $31.6 \%(N=168)$ \\
\hline Multiple VHD & $25.8 \%(N=264)$ & $20.0 \%(N=82)$ & $35.6 \%(N=69)$ & $37.8 \%(N=28)$ & $23.6 \%(N=125)$ \\
\hline CAD without significant stenosis & $31.0 \%(N=318)$ & $31.1 \%(N=128)$ & $30.7 \%(N=58)$ & $39.2 \%(N=29)$ & $21.5 \%(N=114)$ \\
\hline CAD with significant stenosis & $42.4 \%(N=434)$ & $36.5 \%(N=150)$ & $34.4 \%(N=65)$ & $17.6 \%(N=13)$ & $50.1 \%(N=266)$ \\
\hline SVD & $14.4 \%(N=147)$ & $13.9 \%(N=57)$ & $14.8 \%(N=28)$ & $9.5 \%(N=7)$ & $15.3 \%(N=81)$ \\
\hline MVD & $28.0 \%(N=287)$ & $22.6 \%(N=93)$ & $19.6 \%(N=37)$ & $8.1 \%(N=6)$ & $34.8 \%(N=185)$ \\
\hline ACS & $21.6 \%(N=223)$ & $10.7 \%(N=44)$ & $13.2 \%(N=25)$ & $5.4 \%(N=4)$ & $31.6 \%(N=168)$ \\
\hline STEMI & $9.4 \%(N=96)$ & $6.8 \%(N=28)$ & $8.5 \%(N=16)$ & $2.7 \%(N=2)$ & $17.3 \%(N=92)$ \\
\hline NSTEMI & $12.4 \%(N=127)$ & $3.9 \%(N=16)$ & $4.8 \%(N=9)$ & $2.7 \%(N=2)$ & $14.3 \%(N=76)$ \\
\hline Death & $52.7 \%(N=540)$ & $54.0 \%(N=222)$ & $43.4 \%(N=82)$ & $43.2 \%(N=32)$ & $57.4 \%(N=305)$ \\
\hline
\end{tabular}

ACS - acute coronary syndrome, CAD - coronary artery disease, MVD - multi-vessel disease, NSTEMI - non-ST elevation myocardial infarction, SVD - single-vessel disease, STEMI - ST elevation myocardial infarction, VHD - valvular heart disease.

of patients $(n=22)$ (Table II). The percutaneous coronary intervention $(\mathrm{PCl})$ was performed in $22.9 \%$ of patients $(n=227)$, with $\mathrm{PCl}$ of $\mathrm{Cx}$ in $13.2 \%(n=136)$, and $\mathrm{PCl}$ of LAD in $11.2 \%$ (Table III).

Fifty-four percent of patients underwent cardiac valvular surgery $(n=539)$. Thirty percent of these procedures were combined with coronary artery bypass grafting. TAVI was performed in $3.2 \%$ of severe aortic stenosis patients. Seventy-four subjects underwent $\mathrm{PCl}$ during follow-up (7.4\%) (Table IV).

$52.7 \%(n=540)$ of patients died during follow-up; $62.9 \%$ of them ( $n=132$ ) had severe mitral regurgitation, $78.6 \%(n=33)$ significant stenosis of the left main coronary artery and $72.4 \%(n=92)$ had a history of non-ST elevation myocardial infarction. $43.6 \%$ of patients who underwent cardiac surgery died compared to $68 \%$ who did not have surgery. Interestingly, 17 deaths were reported within the first 14 days of inclusion in the study, 6 of which concerned subjects who underwent surgery (Figure 2).

Multivariate regression analysis - the Wald test - determined aortic regurgitation as the most significant risk factor for mortality (Nagelkerke $R^{2}=0.759$; overall prediction rate $=90.1 \%)$. AVI increased the mortality rate 2.4-fold (OR $=2.39 ; 95 \% \mathrm{Cl}: 5.370-11.065 ; p=0.035)$. An increase of age by 1 year raised the risk of mortality by $0.4 \%(\mathrm{OR}=1.038 ; 95 \% \mathrm{Cl}: 1.005-1.072 ; p=0.022)$. The adjusted hazard ratio for death with follow-up prolongation of 1 year was $2.8(\mathrm{OR}=2.815 ; 95 \% \mathrm{Cl}$ : 2.247-3.526; $p=0.001)$ and coronary artery disease without diagonal stenosis was $0.204(\mathrm{OR}=0.204 ; 95 \% \mathrm{Cl}$ : 0.075-0.561; $p=0.002$ ).

\section{Discussion}

Distribution of gender in the population of the Podlaskie Voivodeship has been unchanged for years. In 2016, men constituted $48.7 \%$ of the Podlaskie Voivodeship's population [10]. In the studied group, the percentage is higher, $56.6 \%(n=579)$, which could be attributed to the fact that male sex is an independent risk factor for the development of degenerative valvular heart disease, coronary artery disease and acute coronary syndrome (Table I). The mean age of the study subjects was $67.1 \pm 10.1$ years, which corresponds to the contemporary medical data, according to which, with the declining rheumatoid etiology of the disease the dominant causes of valvular disease are the degenerative processes associated with old age [11]. This is confirmed by comparative analysis of patients with individual valvular diseases; patients with severe aortic stenosis were older than other patients, $68.1 \pm 10.4$ vs. $66.2 \pm 9.9, p<0.001$, while patients with mitral stenosis, the dominant background of which is rheumatoid processes, were significantly younger, $62.0 \pm 9.4$ vs. $67.0 \pm 10.1, p=0.01$. A significantly lower percentage of men was also present in this group, $36.0 \%$ $(n=9)$ vs. $57.6 \%(n=570), p=0.006$ (Table II).

Changing etiology contributes to a different epidemiology of valvular heart diseases. In the studied group, mi- 


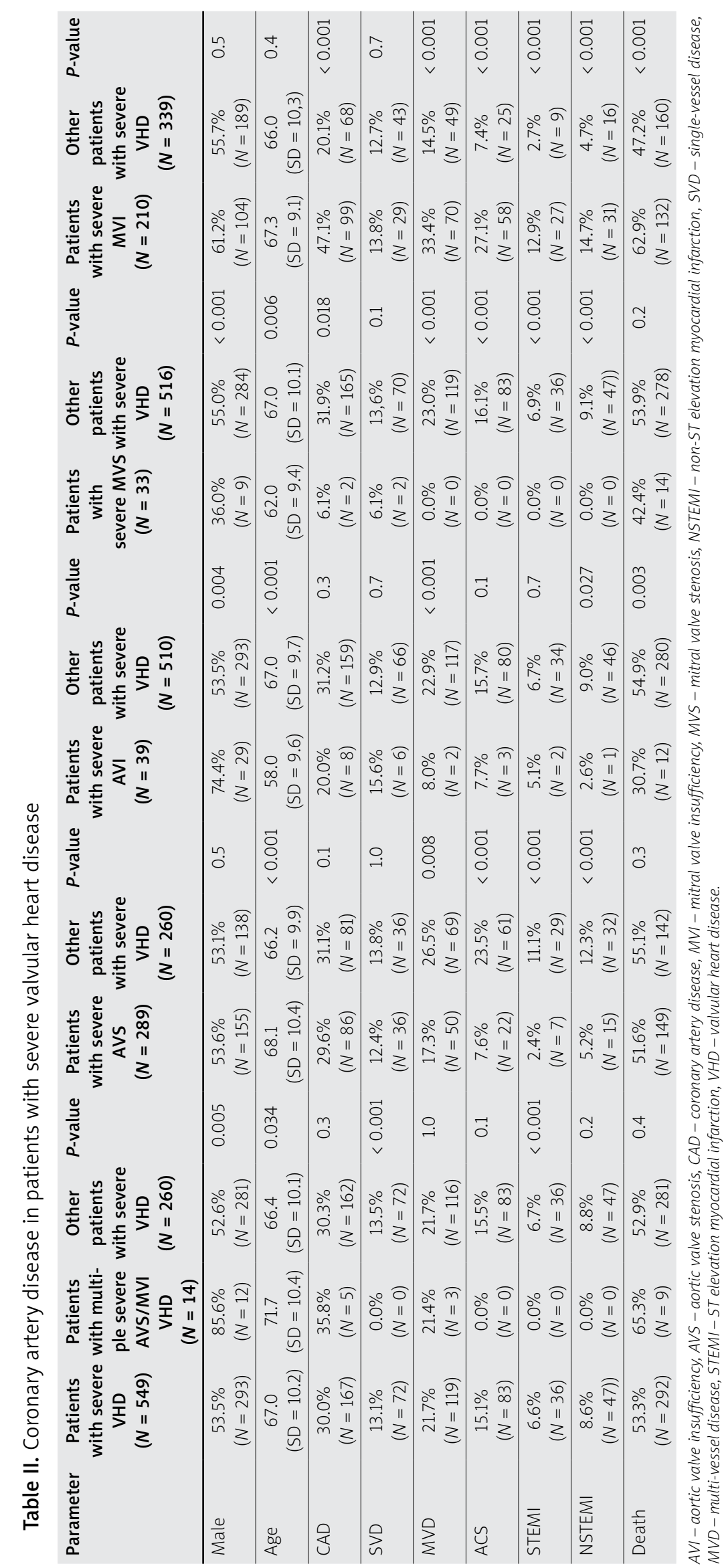




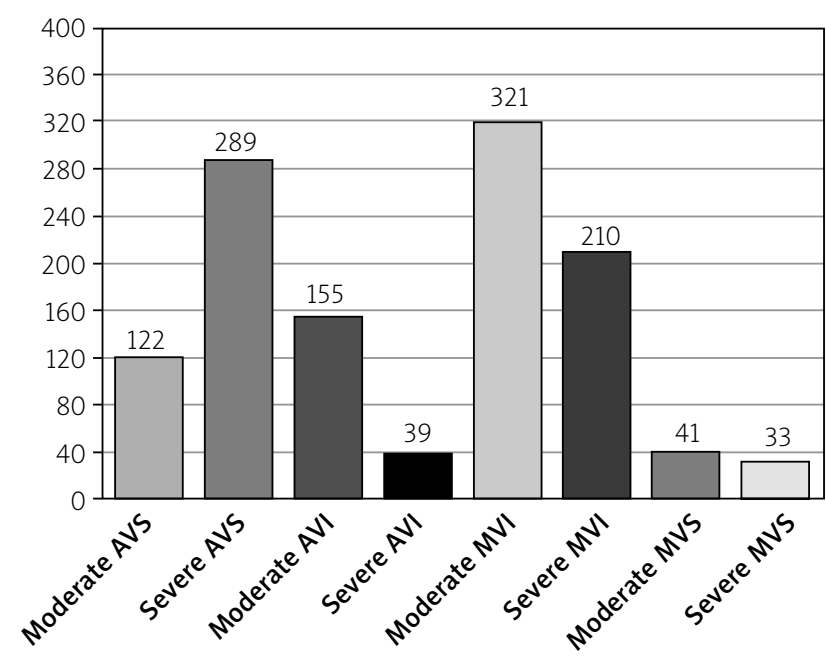

Figure 1. Valvular heart diseases in the study population

tral regurgitation was present in nearly $50 \%$ of patients $(n=531)$. The most prevalent severe valvular disease was aortic stenosis, which occurred in $28.2 \%$ of the subjects $(n=289)$. Similar findings have also been reported in other European studies. In the Euro Heart Survey on Valvular Heart Disease registry, which focused on moderate and severe grades of valvular heart diseases, aortic disease occurred in $44 \%$ of patients, with aortic valve stenosis accounting for $34 \%$ of cases. Mitral valve regurgitation occurred in $25 \%$ of patients, and combined mitral disease in 34\% [3]. The WadPol Registry of Heart Diseases, the largest Polish registry of valvular diseases, includes the history of 1663 patients with acquired valvular heart disease in 2007-2008. The most prevalent one was mitral regurgitation, $38 \%$ of cases, and aortic valve stenosis was found in $27.5 \%$ of patients [4]. The analysis of the valvular diseases etiology revealed the dominance of degenerative over rheumatoid etiology of aortic valve diseases, $50.2 \%$ vs. $30.6 \%$. Mitral valve disease presented a similar etiology pattern, with a degenerative background in $41.2 \%$ of patients, and rheumatoid etiology in every third patient (30.7\%).

In the analyzed group, coronary artery disease occurred in $74.4 \%$ ( $n=752)$, whereas significant angiographic stenoses were observed in $42.3 \%(n=434)$ of patients. The lesions were most commonly found in left anterior descending artery $(24.9 \%, n=256)$, followed by circumflex artery $23.0 \%(n=236)$ and right coronary artery $22.9 \%(n=235)$. Left main coronary artery was the least affected, $4.1 \%(n=42)$ (Table III). Mentioned findings of the atherosclerotic changes in epicardial coronary arteries are similar to the reports in the current literature. The majority of publications on the topography of coronary artery lesions focus on the greater involvement of the left coronary artery in comparison to the right, which is confirmed by numerous autopsy and angiographic studies. LAD is more often affected by atherosclerotic changes and calcifications than RCA and Cx [12]. Similar data are presented in studies evaluating coronary artery calcium score, confirming the predominance of atherosclerosis in LAD, followed by the RCA, Cx and LM [13]. In a retrospective analysis of over 13000 coronarographies, an isolated change in RCA was found in $6.5 \%$ of cases, while a similar lesion was present over five times more frequently in the left artery (34.7\%) [14-17]. Enrico et al. in a study of 73,282 deposits in angio-CT scans of coronary arteries presented similar results by showing that nearly half of them were located in the LAD, and every third in RCA and circumflex artery [18-20]. The analysis also showed that patients with severe aortic stenosis were less often diagnosed with coronary artery disease, which concerned both patients with ischemic heart disease with and without significant atherosclerotic lesions, as well as with multi-vessel disease, $17.3 \%(n=50)$ vs. $26.5 \%(n=69), p<0.001$ (including prior STEMI and NSTEMI), $7.6 \%(n=22)$ vs. $23.5 \%(n=61), p<0.001$ (Table II). Significant atherosclerotic changes in epicardial coronary arteries were less common in all coronary arteries in comparison to the group with other valve defects, whereas the majority of lesions were found in LAD, $17.6 \%$ $(n=51)$. The lower prevalence of coronary disease is also reflected in the analysis of invasive treatment. $9.4 \%$ of patients with severe aortic stenosis underwent $\mathrm{PCl}$ in comparison to $18.8 \%$ of patients with other valvular diseases $(p<0.001)$ (Table III). The lower number of PCls in this group stemmed from the need for valvular surgery, which was combined with surgical revascularization. Valvular cardiac surgery was performed in $81.3 \%$ of patients with severe aortic stenosis and only in $38.4 \%$ of patients with other valvular diseases $(p<0.001)$ (Table IV). These results contradict the hypothesis of a similar pathomechanism and similar risk factors of coronary disease and aortic valve stenosis.

Patients with severe aortic regurgitation had lower prevalence of coronary artery disease with significant atherosclerotic stenoses $(20.5 \%$ vs. $35.7 \%, p<0.03)$, and acute coronary syndrome, $7.7 \%(n=3)$ vs. $15.7 \%(n=80)$, $p=0.1$. Small size of the group and low prevalence of coronary artery disease resulted in a low number of percutaneous coronary interventions and combined procedures (Table IV).

Similar observations were made for the group of patients with severe mitral stenosis. A moderate grade of the disease occurred in only $4 \%$ of patients $(n=41)$ (Figure 1). This group was significantly younger in comparison with other patients, and it was also the only group with the majority of women, with the coexistence of coronary artery disease and acute coronary syndrome noted in individual cases.

Patients with mitral valve insufficiency made up 52\% of the study population, and the subgroup of patients 


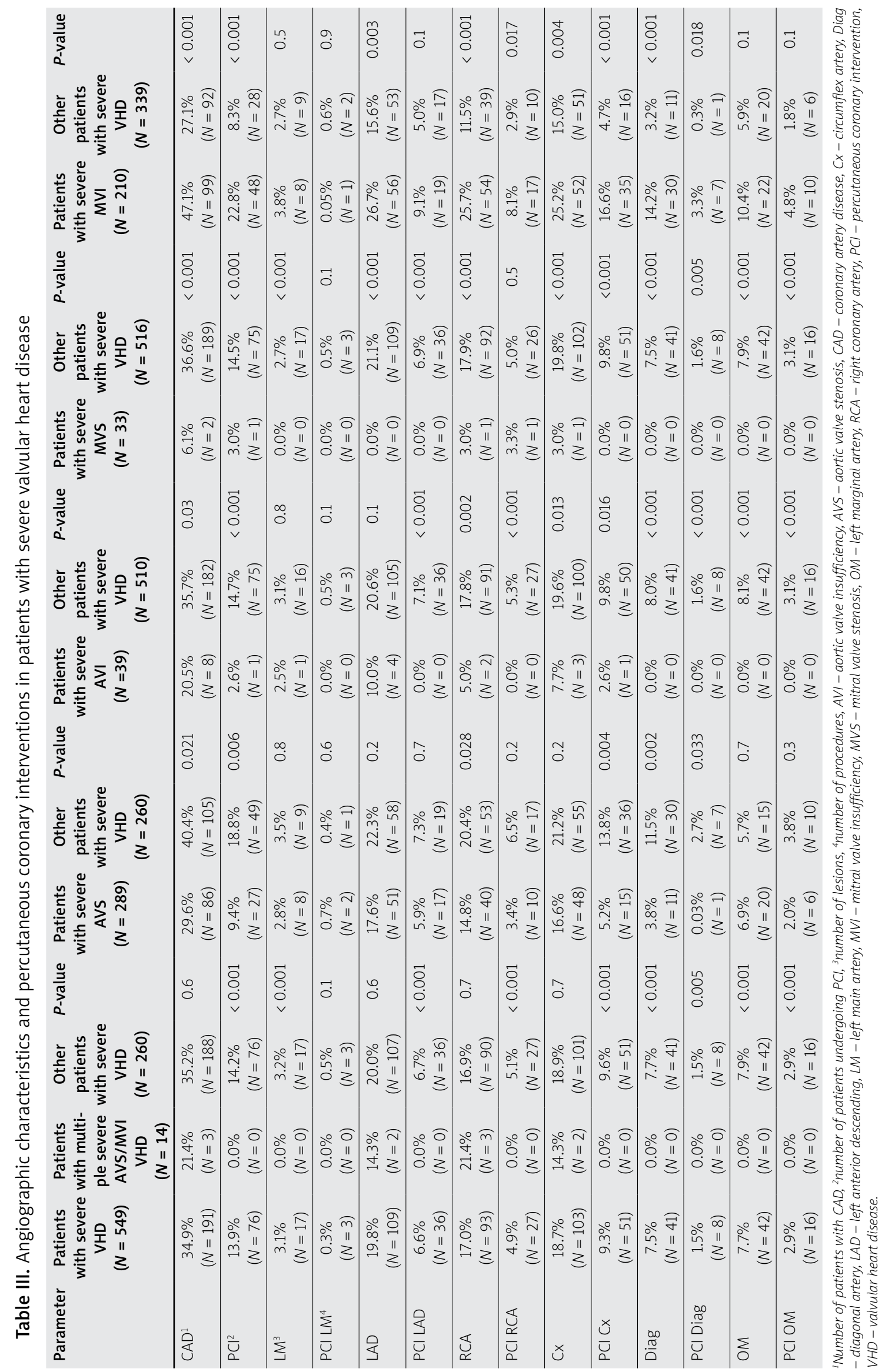




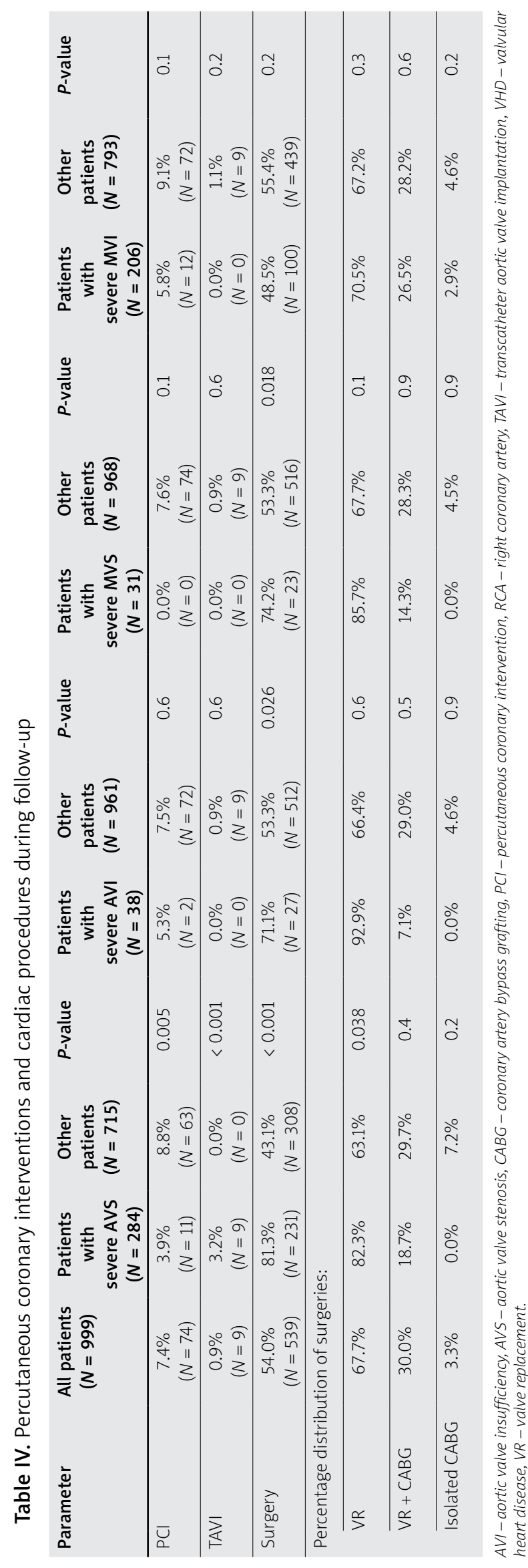

with severe insufficiency accounted for $20.5 \%$ (Tables I and II). $61.17 \%$ of the group $(n=104)$ were men with mean age of $67.3 \pm 9.1$ years. In this group coronary artery disease and acute coronary syndromes were significantly more prevalent, $27.1 \%(n=58)$ vs. $7.4 \%(n=25)$, $p<0.005$, which could suggest more frequent ischemic etiology of mitral regurgitation in this group [21]. Angiographic images revealed that stenosis in LAD (26.7\%, $n=56)$ and RCA (25.7\%, $n=54)$ were the most frequent lesions. Diagonal artery stenosis was significantly more common than in other valvular diseases $(14.2 \%(n=30)$ vs. $3.2 \%(n=11), p<0.001)$ (Table III). Percutaneous coronary angioplasty was performed in $22.8 \%(n=48)$ of patients with severe mitral valve insufficiency vs. $21.19 \%$ with other valvular diseases (Table III). $38.4 \%$ of patients with mitral valve insufficiency underwent cardiac surgery (group with other valvular diseases $49.6 \%, p=0.035$ ) with a combined procedure in every fourth patient.

Fifty-four percent of study subjects underwent surgery, with the highest prevalence of aortic stenosis (81.3\%), which was significantly higher than in the rest of the group $(p<0.001)$. TAVI was performed in 9 cases; in single cases the procedure was combined with planned $\mathrm{PCI}(n=6)$ (Table IV).

In the National Registry of Cardiac Surgery Procedures, the most common are aortic stenosis procedures and surgical revascularization, often in patients with coexisting mitral regurgitation. Multi-valve operations constituting over $10 \%$ of all cardiosurgical procedures [22]. Roques et al. reported $67.3 \%$ of aortic valve procedures and $41.8 \%$ of mitral valve operations. CABG was performed in $20 \%$ of cases. In the study of Ghosh twovalve procedures represented $10 \%$ of all cases, and $32 \%$ patients had a valvular operation combined with CABG $[11,14]$.

$52.7 \%(n=540)$ of patients with valvular heart disease died during the follow-up ( $n=1025)$, regardless of the severity of the defect. The comparison of patients who survived and died found that higher mortality occurred in the group of patients with severe mitral regurgitation, $62.9 \%(n=132)$ vs. $37.1 \%(n=78), p<0.001$. Patients who died more often had significant stenoses in coronary arteries and acute coronary syndromes. Such interdependence was not observed in case of non-significant coronary artery lesions. The independent mortality risk factors were: age $(\mathrm{OR}=1.038 ; 95 \% \mathrm{Cl}: 1.005-1.072$; $p=0.022)$ and aortic regurgitation $(\mathrm{OR}=2.39,95 \% \mathrm{Cl}$ : 5.370-11.065; $p=0.035$ ). In the current literature mortality risk factors in patients with valvular heart disease are: age, type and stage of progression of the valvular defect, low ejection fraction of the left ventricle, coexistence of coronary artery disease, high NYHA class, hypertension, diabetes, chronic kidney disease and pulmonary hypertension. Perioperative risk in patients with valvular heart disease increases with the necessity of additional 


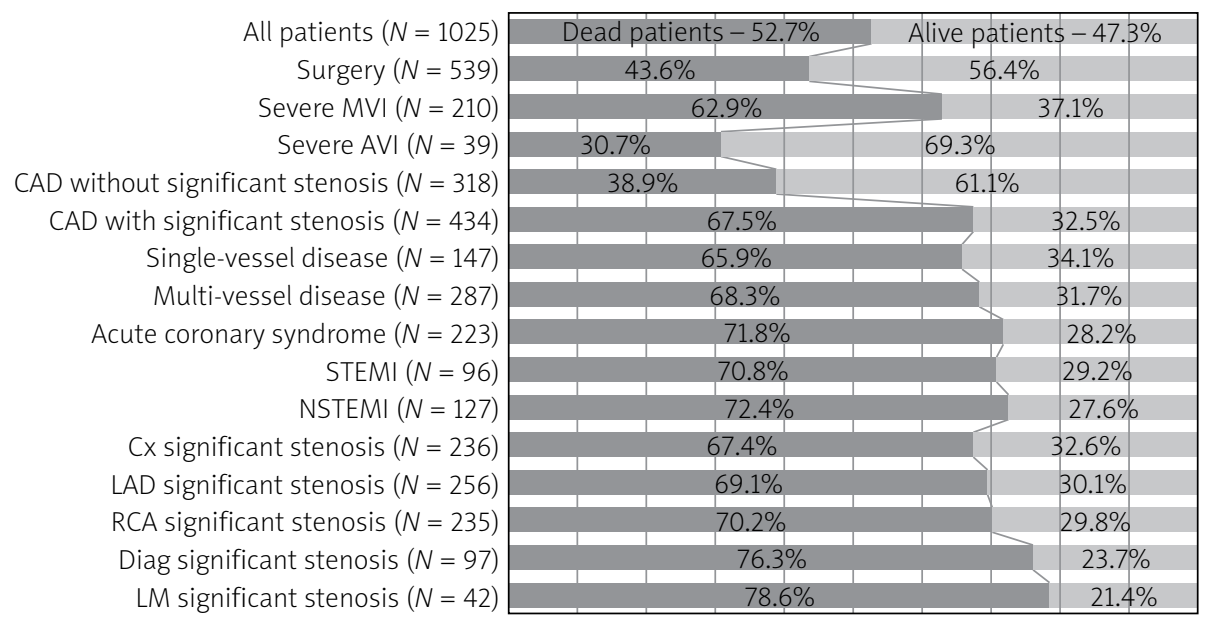

Figure 2. Comparison of dead and alive patients (only significant differences presented, $p<0.05$ )

$A V I$ - aortic valve insufficiency, CAD - coronary artery disease, CX - circumflex artery, Diag - diagonal artery, LAD - left anterior descending, LM - left main artery, NSTEMI - non-ST elevation myocardial infarction, MVI - mitral valve insufficiency, STEMI - ST elevation myocardial infarction, RCA - right coronary artery.

valve repair and surgical myocardial revascularization. The time of qualification for the procedure, before the development of myocardial dysfunction and pulmonary hypertension, is crucial in the prognosis of these patients [15-17].

During the follow-up $43.6 \%$ of patients after cardiac surgery died; $2.46 \%$ of subjects died within the first 14 days after the operation. The highest mortality rate affected patients with multiple valve disease, $65.3 \%$. Those results were similar to the data presented in the literature. According to the ESC EuroHeart registry, periprocedural mortality in single valve procedures is $0.9-3.9 \%$, whereas in multivalve procedures it is $6.5 \%$. In the STS registry the mortality rate in multiple valve procedures accounts for $10 \%$ of cases and is 2 -fold higher compared to a single valve operation [23]. A British registry with data collected between 2004 and 2008 presents periprocedural mortality in aortic valve procedures at the level of $2.8 \%$. Mitral valve repairs resulted in $2 \%$ periprocedural mortality vs. $6.1 \%$ in mitral valve replacements [24]. In the studies conducted during a similar period, 20 -year survival was estimated at $30 \%$ in patients after aortic valve replacement, and $20 \%$ after mitral valve replacement [25]. Peterseim et al. reported 10-year survival in half of cases. Independent mortality risk factors were age, kidney and lung disease, and coronary artery disease [26]. In a study of young adults mean 15-year survival was $80 \%$ in the AVR group and $71 \%$ in the MVR group of patients $[27,28]$.

\section{Conclusions}

Severe aortic stenosis is becoming more prevalent than severe mitral regurgitation in the Polish population. Severe mitral insufficiency coexists with significant stenoses in coronary arteries and with acute coronary syndromes more frequently than other valvular heart diseases. Coronary artery disease is one of the most significant factors worsening the prognosis of patients with acquired heart diseases. LAD stenosis is the most common lesion in the coronary arteries, while severe stenosis of the diagonal artery occurs more often in mitral insufficiency. Non-significant lesions and marginal branch stenosis had no influence on survival. Acute coronary syndrome is an additional burden in the group of patients with valvular heart diseases. The independent risk factors for death were coexisting aortic valve insufficiency and age. The worst prognosis was in the group of patients with severe $\mathrm{MVI}$, which may result from higher prevalence of coronary artery disease in this group. A lesser burden of coronary artery disease and acute coronary syndrome in the group of patients with severe AVS did not affect survival.

\section{Conflict of interest}

The authors declare no conflict of interest.

\section{References}

1. Strzelecki Z, Szymborski J. Zachorowalność i umieralność na choroby układu krążenia a sytuacja demograficzna Polski. 2015; 1-28. Available at: https://bip.stat.gov.pl/files/gfx/bip/pl/ zamowieniapubliczne/426/248/1/81_gp_rrl_2015_monografia_kardiologiczna.pdf.

2. Ray S. Changing epidemiology and natural history of valvular heart disease. Clin Med 2010; 10: 168-71.

3. lung B, Baron G, Butchart EG, et al. A prospective survey of patients with valvular heart disease in Europe: The Euro Heart Survey on valvular heart disease. Eur Heart J 2003; 24: 1231-43.

4. Hryniewiecki T, Stępińska J. WadPol - POLKARD. Ogólnopolski Rejestr Nabytych Wad Zastawkowych. Kardiol Pol 2009; 67; W169 (abstr.).

5. McMurray JJ, Adamopoulos S, Anker SD, et al. ESC Guidelines for the diagnosis and treatment of acute and chronic heart failure. Eur J Heart Failure 2012; 14: 803-69. 
6. Departament Badań Demograficznych GUS. Prognoza ludności Polski na lata 2008-2035, Główny Urząd Statystyczny. 2018; 147-190. Available at: https://stat.gov.pl/cps/rde/xbcr/gus/L_ prognoza_ludnosci_na_lata2008_2035.pdf.

7. Toggweiler S, Zuber M, Surder D, et al. Two-year outcomes after percutaneous mitral valve repair with the MitraClip system: durability of the procedure and predictors of outcome. Open Hear 2014; 1: e000056.

8. Moat NE, Ludman P, De Belder M, et al. Long-term outcomes after transcatheter aortic valve implantation in high-risk patients with severe aortic stenosis: The U.K. TAVI (United Kingdom transcatheter aortic valve implantation) registry. J Am Coll Cardiol 2011; 58: 2130-8.

9. Mohr FW, Holzhey D, Möllmann H, et al. The German Aortic Valve Registry: 1-year results from 13680 patients with aortic valve disease. Eur J Cardiothorac Surg 2014; 46: 1-9.

10. Departament Badań Demograficznych GUS. Ludność według, płci, województwa i podregionów 2016. Available at: http:// demografia.stat.gov.pl/bazademografia Assessed February 28, 2019.

11. Ghosh P. Changing trends in valve surgery in Europe: 1991 2000. J Heart Valve Dis 2004; 13: 1-10.

12. Giannoglou GD, Antoniadis AP, Chatzizisis YS, et al. Difference in the topography of atherosclerosis in the left versus right coronary artery in patients referred for coronary angiography. BMC Cardiovasc Disord 2010; 10: 26.

13. Wasilewski J, Niedziela J, Osadnik T, et al. Predominant location of coronary artery atherosclerosis in the left anterior descending artery. The impact of septal perforators and the myocardial bridging effect. Kardiochir Torakochir Pol 2015; 12: 379-85.

14. Roques F, Nashef SA, Michel P, et al. Risk factors and outcome in European cardiac surgery: analysis of the EuroSCORE multinational database of 19030 patients. Eur J Cardiothorac Surg 1999; 15: 813-6.

15. Edwards FH, Peterson ED, Coombs LP, et al. Prediction of operative mortality after valve replacement surgery. J Am Coll Cardiol 2001; 37: 885-92.

16. Hamamoto M, Bando K, Kobayashi J, et al. Durability and outcome of aortic valve replacement with mitral valve repair versus double valve replacement. Ann Thorac Surg 2003; 75: 24-8.

17. Mihaljevic T, Lam BK, Rajeswaran J, et al. Impact of mitral valve annuloplasty combined with revascularization in patients with functional ischemic mitral regurgitation. J Am Coll Cardiol 2007; 49: 2191-201.

18. Niedziela J, Osadnik T, Roleder M, et al. Atherosclerotic plaque burden distribution in the coronary arteries. The myocardial bridging effect. Choroby Serca Naczyń 2015; 12: 19-24.

19. Lee S, Choi EK, Chang HJ, et al. Subclinical coronary artery disease as detected by coronary computed tomography angiography in an asymptomatic population. Korean Circ J 2010; 40: 434-41.

20. Enrico B, Suranyi P, Thilo C, et al. Coronary artery plaque formation at coronary CT angiography: morphological analysis and relationship to hemodynamics. Eur Radiol 2009; 19: 837-44.

21. Mihaljevic T, Lam BK, Rajeswaran J, et al. Impact of mitral valve annuloplasty combined with revascularization in patients with functional ischemic mitral regurgitation. J Am Coll Cardiol 2007; 49: 2191-201.

22. Maruszewski B TZ. Raport Krajowego Rejestru Operacji Kardiochirurgicznych KROK-POLKARD. 2016. Available at: www.krok. org.pl.
23. Unger P, Dedobeleer, Cosyns B, et al. Mitral regurgitation in patient with aortic stenosis undergoing valve replacement. Heart 2010; 96: 9-14.

24. The Sixth National Adult Cardiac Database Report 2008, $6^{\text {th }}$ edn. Society for Cardiothoracic Surgery in Great Britain and Ireland, 2009.

25. Oxenham H, Bloomfield P, Wheatley DJ, et al. Twenty year comparison of a Björk-Shiley mechanical heart valve with porcine bioprostheses. Heart 2003; 89: 715-21.

26. Enriquez-Sarano M, Akins CW, Vahanian A. Mitral regurgitation. Lancet 2009; 373: 1382-94.

27. Peterseim DS, Cen YY, Cheruvu S, et al. Long-term outcome after biologic versus mechanical aortic valve replacement in 841 patients. J Thorac Cardiovasc Surg 1999; 117: 890-7.

28. Ruel M, Kulik A, Lam BK, et al. Long-term outcomes of valve replacement with modern prostheses in young adults. Eur J Cardiothorac Surg 2005; 27: 425-33. 